\title{
Exploring the usefulness of a simple linear regression model for understanding price movements of selected recycled materials in the UK
}

\author{
A. Angus*, M. Rivas Casado* ${ }^{+}$and D. Fitzsimons^ ${ }^{\wedge}$
}

\author{
*Building 42 a, School of Applied Science, Cranfield University, Cranfield, MK43 0AL; \\ TEL +44 (0)1234 750111, FAX +44 (0) 1234750875 \\ ^ Oakdene Hollins Ltd, Pembroke Court, 22 - 28 Cambridge Street, Aylesbury, Bucks HP20 \\ $1 \mathrm{RS}$ \\ ${ }^{+}$Corresponding author
}

\begin{abstract}
The price volatility of recycled materials exposes many different organisations to financial and regulatory risk. These risks can be partially mitigated by improved understanding of price volatility using econometric models, although these have tended to be sophisticated autoregressive models, beyond the analytical capability or cost structure of the average market participant. In this context, this study explores the use of a simple linear regression model to understand the behaviour of prices for recycled plastic, recovered paper and glass, based on the price of their primary inputs, with a specific focus on the UK market. The results of the simple regression model are compared with a wavelet analysis to determine what information is lost in the trade off with simplicity. Both models found significant relationships between the price of crude oil/ethylene/naphtha and recycled plastics and it appears that there is no loss in model performance by using oil as the explanatory variable, rather than direct inputs (ethylene/naphtha). However, few correlations were found for recovered paper and glass. Initial findings from the wavelet analysis suggest that since 2004 the oil price has become more closely linked to the price of recycled plastics. However, particular dynamics of UK markets for recycled materials may affect price development in a way that would not be repeated on international markets.
\end{abstract}

Keywords: recycled materials; prices; simple linear regression; wavelet analysis 
Recycling of household refuse is largely driven by government objectives to divert waste from landfill (Schaik and Reuter, 2004; Alwaeli, 2010; Otegbeye et al., 2009). For, instance, 40 per cent of waste generated in the EU will be covered by recycling obligations by 2020 (European Topic Centre on Sustainable Consumption and Production, 2010). Therefore, the market for recycled material is only partially connected to market drivers as some market participants are legally obliged to participate, rather than being motivated by profit maximisation. This creates interesting dynamics, where the supply of recycled materials is price inelastic (Stromberg, 2004) and even in a recession, the supply of recycled materials will continue to flow onto the market, despite a lack of demand. For example, amid the 2008 global credit crisis, approximately 15 per cent of all material recycled in the UK was awaiting a buyer, stretching available storage facilities to their limit (The Daily Telegraph, 2008).

A wide range of organisations are vulnerable to the risks posed by such imbalances and resulting volatility (Stomberg, 2004; Edgren and Moreland, 1989). For instance, in the US the price of paper increased from virtually zero to $\$ 200$ per tonne between 1993 and 1995, before falling back to around \$50 per tonne by 1996 (Ackerman and Gallagher, 2002; North Carolina Department of Environment and Natural Resources, 1998). Similarly in the UK, in 2008 , mixed plastics became virtually worthless falling from $£ 200$ per tonne and mixed paper fell from $£ 52.5$ to $£ 6$ per tonne, leaving large stock piles of low value material (The Times, 2008). This volatility causes several undesirable effects. Firstly it creates uncertainty among market actors, disrupting investment decisions (OECD, 2006; Stromberg, 2004). Ackerman and Gallagher (2002) reported on the consequences of the US spike in recycled paper prices (1993-1995), which prompted the investment of approximately $\$ 1$ billion to in recycled paper mills, most of which had closed by 1997.

The continued volatility in the markets for recycled commodities makes it important to develop tools that promote a better understanding of price behaviour among a wide range of stakeholders, using widely available data and less resource intensive statistical techniques. An intuitive way to achieve this is to study the relationship between the price of recycled material and the price of their primary equivalents, for instance, recovered paper can be used as a substitute for wood pulp. Several studies have sought to find methods to relate prices and quantities in primary and recycled markets, although the majority of this research was undertaken in the 1980s and early 1990s, when recycling rates were lower than present (Xiarchos and Fletcher, 2009).

A recent analysis by Blomberg and Soderholm (2009) constructed a model to examine the economics of secondary aluminium production in Europe. They found that changes in the price of secondary aluminium were closely correlated with changes in the cost of primary aluminium, but in the short-run, secondary aluminium is price inelastic and price movements are tightly bound by the availability of scrap processing facilities. Xiarchos and Fletcher (2009) used multivariate time series methods to analyse the interactions, in terms of price and volatility transmission, between primary and secondary markets for copper, lead and zinc between 1984 and 2001 in the U.S. They found a long-term correlation between prices for primary and secondary products for all metals analysed, but found that arbitrary market fluctuations caused this relationship to falter in the short term.

Outside the metal markets, Ackerman and Gallagher (2002) studied the causes of price volatility in the U.S. market for recycled paper market by developing an econometric model 
that examined the correlation between the price of recycled paper and wood pulp. They found the price of recycled paper was correlated to the previous month's pulp price and the paper industry's capacity utilisation.

The previous studies show that constructing a model based on the hypothesis that there is price transmission between primary and secondary markets is reasonable. This study will test this hypothesis using a range of materials outside the metal markets, namely: plastics, glass and paper. This study will take a UK perspective, as the UK is a major stakeholder in the EU recycling sector, which is strategically important because of its environmental and economic credentials (Johnson et al., 2008; Tam, 2008). Currently, the EU recycling sector comprises approximately 60,000 firms, employing 500,000 people, managing 50 per cent of the world's recycled material, with a gross turnover of $€ 24$ billion (European Commission, 2010). Much of this material is exported from the EU, particularly to Asia, but the majority of recycled metals are traded exports between EU Member States (European Commissions 2009a). In economic terms the UK recycling sector is particularly important. In 2009 four of the top ten and nine of the top 25 largest recycling firms were from the UK (European Commission, 2009b).

This paper will explore the usefulness of using a simple linear regression model to better understand oscillations in the prices of recycled materials in the UK, comparing this with the more sophisticated approach of wavelet analysis, to determine how much information is lost in the trade off with simplicity and whether this loss is significant from an economics perspective. Furthermore, as far as we are aware this paper provides the first use of wavelet analysis for examining linkages between markets for primary and recycled materials.

\section{$2 \quad$ Material and methods}

\subsection{Data collected}

Price data for recycled materials were taken from letsrecycle.com, an independent UK website providing information for businesses, local authorities and community groups involved in recycling and waste management. Primary commodity price data were taken from DataStream a subscription service provided by Thomson Reuters, which provides historical prices for a range of commodities. Although the DataStream service is subscription access, data on daily primary commodity prices can be sourced free of charge from various exchanges. The finished product, primary commodities and recycled equivalents considered in this study are listed in Table 1.

\section{Insert Table 1 near here}

Typically there is a range of prices reported for recycled materials, which reflects the variation in regional market structure, transport costs, quality of material and bargaining power (OECD, 2006). For the purpose here, the mean price of a particular recycled material was taken for each month covered by the datasets. Similar data collection techniques were used by the UK Government when describing recycling markets in their "Waste Strategy for England 2007". The historical dataset covered the period 1999 to 2009. Monthly price data, converted from dollars to Sterling, were taken for Datastream to ensure the monthly raw material prices could be directly compared with price data for recycled material (prices for 
recycled materials were taken from UK markets). Table 2 provides further details on the primary commodity prices used.

\section{Insert Table 2 near here}

\subsection{Simple linear regression model}

A simple linear regression model was fitted to investigate the relationship between the price of primary products and its recycled equivalents in the UK. Simple linear regression models are represented by an equation of the form:

$y_{i}=\beta_{0}+\beta_{1} x_{i}+\varepsilon_{i}$

Eq 1.

Where $y_{i}$ is the $i$ measurement of the dependent variable, $\beta_{0}$ and $\beta_{1}$ are regression coefficients known as the intercept and the slope respectively, $\mathrm{x}_{\mathrm{i}}$ is the $\mathrm{i}$ measurement of the independent variable and $\varepsilon_{\mathrm{i}}$ is its associated error term (Gujarati and Porter, 2010).

Market price fluctuations are transmitted from primary to recycled commodities (Xiarchos and Fletcher, 2009), hence, in this study the primary commodity was considered to be the independent variable and the recycled equivalent the dependent. The primary commodities and their recycled equivalents are constituents of finished products, and so can be considered as interchangeable in the production process (Blomberg and Soderholm, 2009). This takes the view that primary and recycled products have high cross-price elasticity where the price of the recycled material should shadow movements of the primary commodity price. In the case of plastics, given that both ethylene and naphtha are by-products of crude oil, a simple linear regression model was also fitted using the price of Brent crude oil as independent variable. The relationship with other explanatory variables (i.e. electricity price, interest rate and GDP growth) was also assessed.

Simple linear regression models perform best when the analytical assumptions are met. These assumptions require: (1) linearity in the parameters (i.e. the dependent variable is a linear function of a constant term, the independent variable and the error term); (2) independent error terms; and (3) the error term to be normally distributed with mean 0 and constant standard deviation (Gujarati and Porter, 2010). A set of tests were carried out to ensure the validity of these assumptions within the fitted model. These included in analytical order the following:

- inspection of data series for outliers using box-plot, histograms, QQ-plots and descriptive statistics. Outliers were removed when they were larger than 3 times the standard deviation of the data series and their value was a stand out from the general expected pattern;

- assessment of normality within each data series using histograms, QQ-plots, as well as measures of skewness, kurtosis, mean and standard deviation. Data were transformed were normality was not present. A Box-Cox transformation was used in all cases (Sokal and Rohlf, 1995);

- assessment of the most appropriate functional form. A linear relationship was considered to be representative after visually comparing the time series to gauge the likely transmission of primary to secondary prices. The Pearson's correlation coefficient was estimated to quantify the linear relationship between variables; 
- inspection of residual plots vs. independent variable for trend patterns (i.e. autocorrelation in the residuals) and systematic over-prediction and/or underprediction patterns; and

- inspection of residual plots vs. independent variable for patterns of asymmetric dispersion (i.e. heterocedasticity) or values deviated from zero and,

- general assessment of model parameters indicating assumption violation (e.g. large standard errors or confidence intervals for the regression coefficients).

The overall validity of the model was assessed using the F-test. Models with $p$-value $<0.05$ were considered to show statistically significant linear relationships. The R-squared and the adjusted R-squared were used to compare model performance.

\subsection{Wavelet analysis}

Simple linear regression analysis is based on the assumption that the relationship between dependent and independent variables is constant over time. This may not hold when dealing with commodity prices because of arbitrary market fluctuations (Xiarchos and Fletcher, 2009). Also, simple linear regression models may fail to identify correlation between time series when there is a time lag between dependent and independent variables, such as the month lag found between the price of recycled paper and pulp (Ackerman and Gallagher, 2002). In this study, wavelet analysis has been implemented to further detect correlation between time series and identify the detail lost by focussing on simple statistical approaches.

Wavelet methods are a multi-resolution analysis used to obtain a time-frequency representations of a continuous signal (Meyer, 1993; Nason, 2008; Walnut, 2002; Grinsted et al. 2004). The objective of the analysis is to decompose a signal (i.e. time series), expressed as a function of the time variable $t$, into frequency components using wavelets (Boggess and Narcowich, 2001). Wavelets are small waves defined by a function $\psi_{0}(\eta)$, where $\eta$ is a nondimensional time parameter that has zero mean and is localised in both time and frequency space (Farge 1992; Percival and Walden 2000). The wavelet is shifted forward and backward in time, along the localized time index $\eta$, to filter or compress signals. This process is repeated for low and high frequency wavelets by varying the wavelet scale (i.e. stretching and compressing the wavelet).

There are a set of pre-defined and commonly used wavelets designed to have these basic properties (Carmona et al., 1998). In this study the Morlet wavelet is used (Figure 1), which is the most frequently used form of wavelet (Rua and Nunes, 2009; Schlueter, 2010; Rua, 2010). The equation of the Morlet wavelet is as follows:

$$
\psi_{0}(\eta)=\pi^{-1 / 4} e^{i \omega_{0} \eta} e^{-\frac{1}{2} \eta^{2}}
$$

where $\omega_{0}$ is the dimensionless frequency and $\eta$ is the dimensionless time.

The cross-correlation between two time series is analysed using the cross-wavelet transform (XWT) and the wavelet coherence (WTC). For two given time series, $x_{n}(n=1, \ldots N)$ and $y_{n}$ $(\mathrm{n}=1, \ldots \mathrm{N})$ the cross-wavelet transform is calculated as:

$W_{n}^{X Y}(s)=\left|W_{n}^{X Y}(s)\right| e^{n \phi_{n}(s)}$ 
where $\left|W_{n}^{X Y}(s)\right|$ is the cross-wavelet power or amplitude, $\phi_{\mathrm{n}}(\mathrm{s})$ is the phase which indicates the delay between the two signals at time $t$ and scale $s$. The power or amplitude measures the strength of the link between cycles in both time series. The phase $\phi_{\mathrm{n}}(\mathrm{s})$ is represented in the outputs as arrows. If the arrows point right the time series are in phase and if they point left, the time series are in anti-phase. Arrows pointing in any other direction show a lag response between dependent and independent variables. For a given wavelength the phase $\phi_{\mathrm{n}}(\mathrm{s})$ can be transformed into time units as follows:

$L_{s}=\lambda_{s} \frac{\phi_{n}(s)}{360}$

Eq. 4

where $L_{s}$ is the lag in time units between two signals at scale $s, \lambda_{s}$ is the wavelength at scale $s$ and the phase $\phi_{\mathrm{n}}(\mathrm{s})$ is represented in degrees in a Polar coordinate system.

The wavelet coherence is estimated from the XWT and measures the correlation between two time series as a function of frequency (Torrence and Compo 1997). It is interpreted as a correlation coefficient ranging from 0 to 1 . The closer the value is to unity the higher the correlation. Statistically significant wavelet coherences were identified using a point wise test (Grinsted et al. 2004). A cone of influence (COI) was calculated following Torrence and Compo (1997) to determine the region of the XWT and WTC where edge effects (i.e. at the beginning and the end of the data series) need to be excluded.

\section{$3 \quad$ Results}

\subsection{Simple linear regression model}

Figure 2 shows the prices of inputs for making plastic, paper and glass respectively. In all cases the price of primary material is higher than the recycled equivalents. This price premium is proportionately higher for soda ash and wood pulp, than for ethylene and naphtha. Movements in the price of recycled material tend to follow those of the primary commodities in all three cases although this is less pronounced in the paper and glass markets. The similar pattern in all time series suggests a potential linear relationship between variables. The following sections summarise the results for the simple linear regression models.

\section{a Plastics}

The prices of all recycled plastics had a significant positive correlation with their primary equivalents (see Pearson's $r$ in Table 3). For all recycled plastics the model using naphtha as the explanatory variable has better performance (i.e. adjusted $\mathrm{R}^{2}$ value) than the model using ethylene, although both models are statistically significant. In both models the larger adjusted $\mathrm{R}^{2}$ values are for HDPE mixed, followed by HDPE single, then Coloured PET and Unsorted mixed plastics. The models with Clear and Light Blue PET as dependent variable do not perform as well as the other plastics.

The model fitted using crude oil as the independent variable has a similar explanatory power as the models using naphtha, but is more effective for non-HDPE material, and the model performs better than those using ethylene as the independent variable. The simple linear 
regression models fitted using electricity price, interest rate and GDP growth as independent variables were not statistically significant.

\section{Insert Table 3 near here}

Table 4 shows the regression coefficients obtained for the statistically significant models. The sign and magnitude of the intercept $\beta_{0}$ reflect the relative post-collection sorting effort and end market value of the sorted material. A negative $\beta_{0}$ shows that an initial sorting cost is incurred before the material can be sold. The magnitude of $\beta_{0}$ is proportionate to the sorting cost. In the case of ethylene the intercept $\beta_{0}$ for all models, except HDPE mixed are positive, while for naphtha and crude oil, all coefficients are negative with the exception of HDPE single and clear light blue PET. This indicates that HDPE single and clear light blue PET require less post-collection sorting and have more end-markets (and hence value) than mixed collections. In the paper market all recycled materials have an initial sorting cost.

\section{Insert Table 4 near here}

\section{$b \quad$ Paper}

Coloured Letter; Old KLS (Cardboard); and Unsorted Mixed Papers had a non-significant relationship with NBSK and BEKP and as a result were excluded from the analysis. Table 3 and 4 show the results for the remaining recycled papers for the models using NBSK and $\mathrm{BEKP}$ as the independent variable.

Pearson's correlation values between the prices for recycled and primary paper are similar when NBSK and BEKP are used as the independent variable. In both cases, the prices of white letter have the strongest correlation, followed by Sorted Office Paper and Recycled Newspaper and Pamphlets.

c Glass

The model using soda ash and glass was not statistically significant. As with the other recycled materials, correlations were sought between glass and energy prices, the Sterling/Dollar exchange rate and economic growth. A significant correlation was found between oil prices and mixed glass and a non-significant relationship between mixed glass and electricity prices.

\subsection{Wavelet analysis}

a Plastic

Results for the wavelet coherence show that between 2006 and 2008 there were common cyclic features in the time series of ethylene and HDPE single in the $\sim 1$ to 2 year band (Figure 3a). For a high percentage of this significant section both series are in phase. This indicates that HDPE Single prices mirrors ethylene prices and that that there is an immediate price transmission over this period. Both series also have high coherence values in the 6 to 8 months band between 2008 and 2010. The direction of the arrows show that the two series are not in phase during this period, indicating that there was a lag of approximately 0.75 months in transmission from ethylene to HDPE Single prices (Table 5). 
Similar patterns were found between ethylene and HDPE Mixed (Figure 3b), with the presence of common price oscillation between both time series for wavelengths from 1-2 years from 2006 to 2010. As with HDPE Single, this price transmission is immediate. Further statistically significant correlations between both time series can be detected for the 6-8 months and the 2-5 months bands from 2007-2009 and 2007-2008 respectively. In these sections there is a lag of 0.08 months and 0 months respectively (Table 5) between ethylene and HDPE Mixed responses (as shown by the arrows).

For Naphtha and HDPE Mixed, the wavelet coherence showed significant common periods between the two time series for the 4-6 months band from 2004-06, with the band lengthening to 6-24 months from 2006 onwards (Figure 3e). A similar pattern was detected for ethylene/naphtha and clear light blue PET (Figures $3 \mathrm{c}$ and 3f). For ethylene there is a significant correlation at band 6-12 months. For naphtha and CLB PET there are two significant correlations, one occurring at 6-12 months, the other at approximately 24 months between 2004 and 2006. In all cases the lags are negligible (i.e. both series are in phase) for the sections of significant coherence values that fall within the COI: when the price of the raw material increases, the price of recycled material mirrors the increase.

Significant common patterns between the price of ethylene/naphtha/crude oil and coloured PET (Figure 3d, 3g and 3h) were also identified. In all three cases there are sections of significant coherence values at bands ranging from 9 months to 2 years between 2004 and 2008. The series are in phase or have a slight lag (between 0 and 22 months) in price transmission (Table 5).

For mixed plastics, areas of high coherence were only found only for oil prices (Figure 3i), again between 2004 and 2008 for wavelengths from 6 months to 2 years. The series are in phase or have a slight lag in price transmission. No significant periodicity was found for the following: Naphtha and HDPE Single; Naphtha and Coloured PET; Ethylene and oil; HDPE mixed and oil; Ethylene and mixed plastic; Naphtha and mixed plastic; CLB PET and oil.

b Paper

No significant patterns were found for the wavelet coherences within the paper market, so the results are not reported.

c Glass

No significant coherence was found between soda ash and recycled glass. There were some significant coherences within the data, but nothing of significant duration. There are some interesting relationships outside the cone of influence, but more data are required to determine whether these correlations are significant.

The analysis was repeated with recycled glass and crude oil. No significant periodic patterns or correlations were found for green glass and mixed glass. However, significant sections of coherence were found between prices of oil and clear and brown glass respectively (Figure $3 \mathrm{j}$ and $3 \mathrm{k}$ ). For oil and clear glass common patterns between both time series were found for wavelengths of 6 months from 2006 to 2008. For oil and brown glass prices these sections were found for the seven months band between 2004 and 2008, with lags between 3 and 6 months. 


\section{Insert Table 5 near here}

\section{Discussion}

The purpose of this paper was to explore the possibility of using a simple linear regression model with widely available data to enable a wide range of market participants to gain greater understanding of price movements in a domestic market for recycled material, using the UK as a case study. The rationale was to identify the extent to which it is possible to develop simple models for market participants to use to better understand domestic markets. To assess the usefulness of this simple econometric model, wavelet analysis was used to further detect correlation patterns, identifying deficiencies in the simple model.

The first step of the simple linear regression model was to estimate the correlation between the prices of primary and recycled materials. The links between recycled plastics and their primary equivalents has received little attention, relative to the number of analyses on metals. Significant positive correlations were found between the price of crude oil, ethylene and naphtha with the price of most recycled plastic bottles. Similarly, a significant positive correlation was found between the price of NBSK and BEKP pulp and some forms of recycled paper. These findings reinforce other studies that found links between prices in primary and recycled markets (Blomberg and Soderholm, 2009; Xiarchos and Fletcher, 2009; Ackerman and Gallagher, 2002). However, there was no significant correlation between the price of soda ash and cullet, although there was some evidence to link movements in the price of cullet to oil prices.

The cross-wavelet analysis found common cycles between the time series of crude oil/ethylene/naphtha and most recycled plastics (except mixed plastics); no common cyclic patterns were detected for paper and any of the other variables, except for few sporadic sections between paper and oil/cullet prices. These sections were small and probably a coincidence. WRAP (2008) indicated that price of recycled plastic is closely linked to the price of virgin plastic, but the models here suggest that there is also a significant correlation between recycled plastic and the inputs to virgin plastic. This is useful because commodity markets are usually less opaque than markets for finished products (Masih et al., 2010). Thus, it is possible to make relatively accurate forecasts of prices for recycled plastics using widely available crude oil prices as the predictor variable.

All wavelet coherences between recycled plastics and their primary equivalent (oil, ethylene and naphtha) are characterised by significant coherence sections between 2002-2004 and 2006-2008 and one structural break between 2004 and 2006. These patterns conform to particular occurrences in the market for crude oil, as oil prices and petrochemical prices are correlated by as much as $80 \%$ (Masih et al., 2010). The period of 2002-04 was characterised by relative volatility in oil prices and an upward movement in price (Askari and Krichene, 2008). The structural break from 2004-2006 conforms to the period where the gradual increasing demand for oil had eroded OPEC structural stocks (Chatham House, 2006). The period following 2006 was relatively less volatile than the 2002-2005, characterised by an almost interrupted increase to a peak in the summer of 2008, before slumping in Q4 2008 in the wake of the international credit crisis. Since Q1 2009, the oil price has been steadily increasing again. 
The wavelet analysis was also used to identify patterns that are undetected by the simple linear regression model. Simple linear regression models only identify linear relationships between a dependent and an explanatory variable but (i) they do not account for changes in the strength (or functional form) of this relationship over time and (ii) they do not allow a lag response between dependent and independent variables.

For plastics, the cross-wavelet analysis showed that the strength of the correlation between the prices of the recycled material and the primary commodity varied over time. In particular for plastics, common cycles between primary commodity and recycled material initiated around 2004/05. This coincides with the elimination of OPEC stocks and the build up of the oil price to its 2008 peak. It could be speculated that producers of plastic began to price-in higher production costs and began making arrangements to use relatively less expensive secondary material. The linear regression model was unable to detect the emergence of a new price trend, although when checking for outliers in the price data for recycled material, the outliers tended to be from 2008 onwards. Therefore, the simple linear regression model is likely to perform better when fitted to short time intervals. The wavelet analysis is likely to have greater exploratory strength over the medium to long-term because it shows emerging, or fading price trends.

Other studies analysing links between primary and secondary markets have used more advanced regression techniques (e.g. multiple regression and auto-regression). Although the intention here is to strip out such complexity to help new market actors, it must be recognised that there is a possibility that much explanatory power is lost by focussing on the links between the prices of recycled material based on one explanatory variable. The comparison exercise of wavelet analysis suggests that only some findings of correlations in the plastic market are valid. However, observations on the links between wood pulp and recycled paper and crude oil and glass are misleading. This suggests that the paper and glass market are beyond simple regression modelling. More limiting to the use of the simple regression approach is the apparent lag in the transmission of oil to plastic prices. This lag is apparent for most forms of recycled plastics.

It should also be stressed that this is an exploratory study. The rationale was to investigate whether a simple tool could be developed for UK market participants to better understand price dynamics in UK markets for recycled material. However, using an individual country as an example has limitations, as each domestic market will have market characteristics reflecting specific tastes and preferences and well as recycling regulations in that country. These nation specific characteristics may become less influential if European or global markets are analysed. At a wider scale of analysis, it is likely that global influences in primary commodity markets will have a more powerful effect on recycled materials.

The lack of price transmission from soda ash and cullet prices could be a particular characteristic of the UK glass market. The UK produces white (container) glass, with brown and green glass making up a much smaller proportion of production. However, the supply of recycled glass is dominated by green glass, as the UK is one of the largest importers of wine and an oversupply of green and mixed cullet has long been a characteristic of the UK glass market. The floor price for green and mixed cullet is established by the value of Packaging Recovery Notes (PRNs), which are given for cullet use and a substitute use in aggregates at typically £15 per tonne. The surplus of mixed cullet flows into the aggregate market and is exported. This surplus of cullet for remelt perhaps explains why there is little relationship between the price of (mixed) cullet and soda ash in the UK. As the price of soda ash 
increases industry cannot use more cullet as it has already achieved the technical upper limit to using the low cost alternative of cullet. For flint glass the story is more complicated since the UK market is undersupplied. As the price of primary feedstock increases it might be expected that the price of clear cullet would also increase thereby encouraging greater separation of clear cullet. The price for clear cullet is higher than for mixed and should show a closer correlation with the price of primary feedstock. However, the specification for flint cullet is much tighter than for other colours and because the specification for the flint output in the UK is also very strict this limits the quantity of cullet converted to flint glass to typically $35 \%$ of total supply, which is approximately less than half the proportion for green container glass. This again tends to explain the poor link between primary and secondary prices: there would have to be a significant increase in price for energy and primary feedstock for any reasonable price transmission to sufficiently clean cullet. This price increase would also need to be reasonably permanent for suppliers to have any confidence to invest in sorting and cleaning technologies.

The UK paper market also has distinctive qualities. The collection of paper and hence supply of recycled fibre is extremely inelastic, as it is mandated by law, rather than by market forces. Thus the supply and recovery of paper is relatively constant. However, the demand for recovered paper fibres has declined year on year from its peak in 2000. The extent to this decline varies according to type of fibre. Domestic consumption of news and PAMs (periodicals and magazines) and mixed grades, has remained relatively stable, conversely domestic demand for OCC has fallen, but to date the excess supply has found export markets primarily in Asia. Over $50 \%$ of paper in the UK is now exported and the markets for some particular grades of recovered waste are now largely dependent on demand from China (WRAP, 2009). Over the next few years there may be a rebalancing of supply and demand for most grades, as the trend towards lower consumption of paper feeds through to collections. The model results show that the market dynamics of paper in the UK is probably not connected to drivers on international commodity markets.

The area where the model appeared to give promising results was the plastic sector. The price of recycled plastic reflects the strong domestic and global demand for recycled plastic, particularly demand from Asian countries. The increasing use of recovered plastic material on global markets has been largely driven by the relatively low processing costs in importing countries and the increasing cost-effectiveness of recycled plastics relative to virgin plastics. Approximately $90 \%$ of recovered plastic was exported to China in 2009, this was destined for China and around $60 \%$ of the UK's recovered plastic exports are HDPE or LDPE (WRAP, 2006; WRAP, 2011). Domestic demand for recycled plastic is also strong, particularly for: recovered clear PET; natural HDPE bottles; and food-grade recycled plastics. Accordingly prices for these commodities are comparable with prices for virgin polymers (WRAP, 2011). However, Markets for coloured plastics as more limited, which means their prices are relatively low compared with other recycled plastics. Thus, the plastic market in the UK is connected to international markets, where sorting and processing costs are relatively small compared with cullet and paper, but also the price of the primary commodity equivalent has rapidly increased.

The model results for glass and paper reflect the UK market structure, which is atypical of EU or international markets. Using prices from international markets would remove the effects of the specialisation of the UK recovery sector and offer insights into the dynamics of recycled material markets in general. Taking this wider perspective on the economics of recycled material would likely mean that global developments may affect price dynamics too, meaning that international markets may develop in a completely different way to the UK. 
This represents further grounds for study, but goes beyond the scope of this study, which was to understand the extent to which simple market drivers can be used to understand movements in prices. The market fundamentals for recycled markets, probably

\section{$5 \quad$ Conclusion}

The dynamics of markets for recycled products expose many different organisations to the risks posed by characteristic price volatility. These risks include excess investment, inappropriate storage preparation and regulatory failures. These risks can be mitigated to some extent by using models that engender a deep understanding of market dynamics. Previous models have tended to be sophisticated autoregressive models, beyond the analytical capability or cost structure of the average market participant. Therefore, this study explored the use of a simple linear regression model to achieve the same outcome, comparing it to a more complex analysis to determine what information is lost in the trade off with simplicity.

Current UK market intuition has identified a link between the price of recycled plastics and virgin plastic. The models here suggest that this correlation also applies to the commodity inputs to plastic. Both models found significant relationships between the price of crude oil/ethylene/naphtha and recycled plastics. This is useful as market data, particularly for crude oil, is more widely available than information on virgin plastic.

As far as we are aware, this paper presents the first use of wavelet analysis for recycled materials. The wavelet model detected correlations between oil/ethylene/naphtha and recycled plastics, which began post 2004. It was not the purpose of this paper to comment on market development, but it appears that the correlation between the prices of these products became stronger post 2004 and that this links to price movements for crude oil and could suggest an increasing link between the oil market and recycled plastics.

The simple linear regression model identified a significant correlation between wood pulp prices and the price of recycled paper, but this was not supported by the wavelet analysis. Neither model identified a significant relationship between the prices of primary products and cullet. Thus, the models used in this paper appear to be useful only for the plastics markets, suggesting that there are explanatory variables missing from the predictive models for paper and glass. As expected, the simple model would require constant updating and confirmation by a more complex model, such as wavelet analysis, which would partly offset the advantages of using a simple model.

The particular characteristics of the UK markets may influence price dynamics in a way that is not repeated in wider markets. For instance, the UK has a long history of surplus supplies of green and brown glass and the collection of paper is driven by regulation rather than market drivers. These characteristics would be less relevant if the analysis was undertaken using prices from EU or international markets.

\section{References}

Ackerman F, Gallagher K. Mixed signals: market incentives, recycling, and the price spike of 1995. Resour Conserv Recy 2002; 35: 275-295.

Alwaeli M. The impact of product charges and EU Directives on the level of packaging waste recycling in Poland. Resour Conserv and Recy 2010; 54: 609-614. 
Askari H, Krichene N. Oil Price dynamics (2002-2006). Energ Econ 2008; 30: 2134-2153.

Blomberg J, Soderholm P. The economics of secondary aluminium supply: an econometric analysis based on European data. Resour Conserv Recy 2009; 41: 339-364.

Boggess A, Narcowich F. A first course in wavelets with Fourier analysis. New Jersey: Prentice Hall; 2001.

Mitchell J. A new era for oil prices [internet]. London: Chatham House 2006 [cited 2011 April 15]. Available from http://www.chathamhouse.org.uk/files/3350_oilprices0806.pdf

Carmona R, Hwang W, Torresani B. Practical time-frequency analysis. Gabor and wavelet transforms with an implementation in S. Wavelet analysis and its applications. Vol. 9. London: AP Academic Press; 1998.

Commons Select Committee. Waste strategy for England 2007 Inquiry: the role of the export markets [internet]. London: WRAP 2008 [cited 2011 April 15]. Available from http://www.publications.parliament.uk/pa/cm200910/cmselect/cmenvfru/230/8101519.htm

DEFRA, Waste Strategy for England 2007: Annex D: Markets and Materials [internet]. London Defra 2007 [cited 2011 April 15]. Available from:

archive.defra.gov.uk/.../waste/strategy/strategy07/.../waste07-annex-d.pdf

Edgren J, Moreland K. An econometric analysis of paper and wastepaper markets. Resour Energ 1989; 11: 299-319.

European Commission. Recycling: innovation, industry and innovation [internet]. Brussels: EC 2010 [cited 2011 April 15]. Available from:

http://ec.europa.eu/enterprise/policies/innovation/policy/lead-market-

initiative/recycling/index_en.htm

European Commission (2009a). The fall in demand for recycled material [internet]. Brussels: EC 2009b [cited 2011 April 15]. Available from:

http://register.consilium.europa.eu/pdf/en/09/st06/st06918.en09.pdf

European Commission. Study on the Competitiveness of the EU eco-industry [internet]. Brussels: EC 2009b [cited 2011 April 15]. Available from:

http://ec.europa.eu/environment/enveco/jobs/index.htm

Fischer C, Davidsen C. Europe as a recycling society: the European recycling map [internet].

Copenhagen: European Topic Centre on Sustainable Consumption and Production 2010 [cited 2011 April 15]. Available at:

http://eea.eionet.europa.eu/Public/irc/eionet-

circle/etc_waste/library?l=/european_recycling/200810_etc-scp-/_EN_1.0_\&a=d

Farge M. Wavelet transform and their application to turbulence. Annu Rev Fluid Mech 1992; 24: 395-457. 
Grinsted A, Moore J, Jevrejeva S. Application of the cross wavelet transform and wavelet coherence to geophysical time series. Nonlinear proc Geoph 2004; 11: 561-566.

Gujarati D, Porter, D. Essentials of Econometrics. $4^{\text {th }}$ Ed. New York: McGraw Hill; 2010

Johnson, J, Reck, B, Wang, T, Graedel, T. The energy benefit of stainless steel recycling. Energ Policy 2008; 36: 181-192.

Letsrecycle.com [internet] London [updated 15/4/2011; cited 15/4/2011]. Available from http://www.letsrecycle.com/

Masih M, Algahtani I, De Mello L. Price dynamics of crude oil and regional ethylene markets. Energ Econ 2010: 32: 1435-1444.

Meyer Y. Wavelets, algorithms and applications. Society for Industrial and Applied Mathematics. Philadelphia; PA. 1993.

Nason G. Wavelet methods in statistics with R. London: Springer; 2008.

North Carolina Department of Environment and Natural Resources. Paper: office paper commodity profile [internet]. North Carolina Department of Environment and Natural Resources [cited 2011 April 15]. Available from: http://www.p2pays.org/ref/02/0162222.pdf

OECD. Improving recycling markets [internet]. Paris: Organisation for Economic Cooperation and Development 2006 [cited 2011 April 15]. Available from:

http://www.oecd.org/document/14/0,3343,en_2649_34395_37757966_1_1_1_1,00.html

Otegbeye M, Abdel-Malek L, Hsieh H, Meegoda, J. On achieving the state's household recycling target: a case study of Northern New Jersey, USA. Waste Manage 2009; 29: 647654.

Percival D, Walden A. Wavelet methods for time series analysis. Cambridge: Cambridge University Press; 2000.

Rua, A. (2010). Measuring co-movement in the time-frequency space. J Macroecon 2010; 32: 685-691.

Rua A, Nunes, L. International co-movement of stock market returns: a wavelet analysis. $J$ Empir Financ 2009; 16: 632-639.

Sokal R, Rohlf F. Biometry: the principles and practice of statistics in biological research. $3^{\text {rd }}$ Ed. New York: W.H Freeman and Co 1995.

Schaik A, Reuter, M. (2004). The time-varying factors influencing the recycling rate of products. Resour Conserv Recy 2004; 40: 301-328.

Schlueter S. A long-term/short-term model for daily electricity prices with dynamic volatility. Energ Econ 2010; 32, 1074-1081. 
Stromberg P. Market imperfections in recycling markets: conceptual issues and empirical study of price volatility on plastics. Resour Conserv Recy 2004; 41: 339-364.

Tam V. Economic comparison of concrete recycling: a case study approach. Resour Conserv Recy 2008; 52: 821-828.

The Daily Telegraph. Mountains of recycled rubbish spring up across UK as market for waste collapses [internet]. London: The Daily Telegraph 2008 [cited 2011 April 15]. Available from:

http://www.telegraph.co.uk/earth/environment/4015775/Mountains-of-recycled-rubbishspring-up-across-UK-as-market-for-waste-collapses.html

The Times. Recycling waste piles up as prices collapse [internet]. London: The Times 2008 [cited 2011 April 15]. Available from:

http://www.timesonline.co.uk/tol/news/environment/article5093545.ece

Torrence C, Compo P. A practical guide to wavelet analysis. B Am Meteorol Soc 1997; 79: $61-78$.

Walnut D. An introduction to wavelet analysis. Boston: Birkhauser; 2002.

http://www.wrap.org.uk/downloads/MSR_Redesign_June_2011.ddc51899.10876.pdf

WRAP. Realising the value of recovered paper: An update [internet].

http://www.wrap.org.uk/downloads/WRAP_Paper_market_situation_report_Feb2010.b38071 0b.8440.pdf

WRAP. Realising the value of recovered plastics: market situation report Autumn 2007 [internet]. Banbury: WRAP 2008 [cited 2011 April 15]. Available from: www.wrap.org.uk/document.rm?id=4755

WRAP. UK Plastics Waste - A review of supplies for recycling, global market demand, future trends and associated risks [internet]. Banbury: WRAP 2006 [cited 2011 October 25]. Available from: http://www.wrap.org.uk/downloads/UK_Plastics_Waste.baf66ca6.5543.pdf

Xiarchos I, Fletcher, J. Price and volatility transmission between primary and scrap metal markets. Resour Conserv Recy 2009; 53: 664-673. 